\title{
¿Por qué es necesario reconstruir el Sistema Nacional de Educación Pública en Chile?
}

\author{
Manuel Riesco LaRRaín \\ Francisco DurÁn del FierRo
}

Resumo: Este trabalho examina o sistema educacional chileno implantado na ditadura e orientado por princípios neoliberais. Seu objetivo é alertar, mediante indicadores, documentos e diálogo com autores críticos deste modelo, para a necessidade de reconstruir o sistema nacional de educação pública.

Palavras-chave: Educação; Sistema Público; Chile.

\section{Manuel Riesco \\ LARRAÍN}

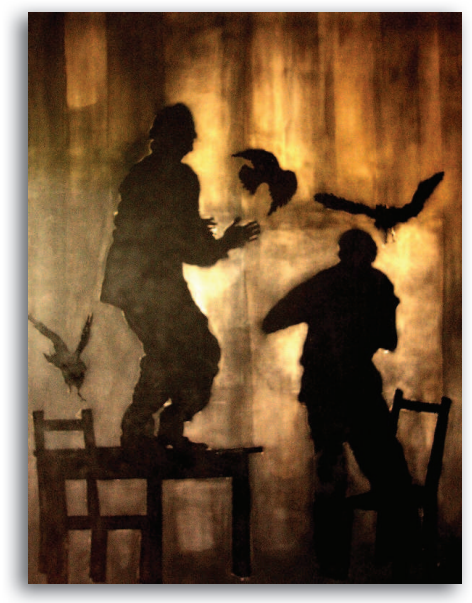

Mestre em Economia e professor da Universidad de Valparaíso e da Universidad ARCIS; vicepresidente do Centro de Estudios Nacionales de Desarrollo Alternativo (CENDA).

\section{Francisco Durán Del FIERRO}

Sociólogo e graduado em Políticas Públicas. Pesquisador do Centro de Estudios Nacionales de Desarrollo Alternativo (CENDA) e editor geral do Foro Aequalis de Educación Superior.

\section{Why rebuild Public Educational System in Chile?}

Abstract: This paper examines the Chilean educational system deployed in dictatorship and guided by neoliberal principles. Its goal is to contribute, through indicators, documents and dialogue with authors that have critics to this model, the need to rebuild the national system of public education.

Keywords: Education; Public System; Chile. 


\section{INTRODUCCIÓN}

Durante el 2011 las calles de numerosas ciudades en Chile estuvieron marcadas por un ánimo común: el malestar. Este se relacionaba con un sistema político y económico que, según vociferaban, los excluía de todos los ámbitos de decisión. Esta suerte de "dolor social" ha conducido a diferentes consecuencias, las que, sin embargo, no han logrado reorientar el contenido esencial de lo criticado.

Sin perjuicio de esta incapacidad de cambio sistémico y estructural del movimiento social, cabe destacar y valorar la consolidación de un espacio deliberativo en torno al cual se ha avanzado en objetivos comunes.

En ese escenario se enmarca el presente análisis crítico, el cual apunta a expresar una necesidad, tanto desde un punto de vista económico como social, que inevitablemente se trasmuta en una posibilidad real. En ese sentido, se explicita el origen de la denominada "crisis de la educación" y se analizan los mitos que recorren el discurso que legitima el sistema como actualmente está concebido.

Para dar coherencia y consistencia a lo anteriormente expuesto, se identifican una serie de elementos que determinan la lógica interna del sistema de financiamiento; esto es, su ineficiencia, injusticia, insostenibilidad y perversidad. Específicamente, se recorren los intersticios de las diferentes formas de financiar la educación y los mecanismos prevalecientes que permiten concluir en la necesidad de un cambio profundo de los pilares que lo inspiran y sostienen.

\section{ORIGEN DE LA CRISIS ACTUAL: EL DESMANTELAMIENTO DEL SISTEMA NACIONAL DE EDUCACIÓN PÚBLICA}

En 1973, el Estado de Chile matriculaba un 30\% de su población total en establecimientos gratuitos y de reconocida buena calidad, pertenecientes al sistema nacional de educación pública, en todos sus niveles (RIESCO, 2007). Constituyó uno de los principales logros históricos de la obra desarrollista de una sucesión de gobiernos, de variados tintes políticos, principalmente de aquellos que, a lo largo del medio siglo que va desde el 11 de septiembre de 1924 hasta el 11 de septiembre de 1973, transformaron de arriba abajo la sociedad chilena. 
Al término de la dictadura, esto es, en 1990, dicha proporción se había reducido al 25\%, considerando a todos los matriculados en establecimientos educacionales, públicos y privados, en todos los niveles. El 2009 alcanzó al 26\% de los habitantes del país (CENDA, 2011a). Es decir, hay menos chilenas y chilenos de todas las edades estudiando hoy que hace cuarenta años, en proporción a la población total. Si paralelamente se ha logrado aumentar la cobertura en los distintos niveles educacionales, como proporción de las cohortes de edades correspondientes - con una tasa de cobertura del 43\% para el 2010 (ORELLANA, 2011) - ello se debe a que los jóvenes han reducido considerablemente su número en relación a la población. Incluso con la proliferación actual de instituciones privadas no se ha podido igualar el esfuerzo realizado a comienzos de los años 1970.

La dictadura desmanteló en sus pilares fundamentales el sistema nacional de educación pública, puesto que la consideraba una plaza estratégica del denominado "enemigo interno". Azuzados por la vieja élite agraria y sus herederos, tras recuperar los privilegios que creyeron perdidos irremediablemente, culpaban al sistema público de haber promovido los cambios políticos, al haber despertado al pueblo de la siesta secular de su vida campesina tradicional. Y no dejaban de tener razón.

La dictadura intervino colegios y universidades, cerró escuelas, departamentos y facultades, incluido el Instituto Pedagógico de la Universidad de Chile, y desfinanció gradualmente el sistema. Al cabo de una década, había menos alumnos matriculados, especialmente en las universidades. Posteriormente, desmantelaron su estructura nacional, fragmentando colegios y universidades por municipios y regiones de forma inconexa y desarticulada.

En las décadas posteriores, un grupo económico, esto es, los grandes rentistas - corporaciones mineras, hidroeléctricas, forestales, pesqueras y otras, aparte de monopolistas de todo tipo - lograron una hegemonía desproporcionada en la élite chilena. Ellos obtienen la mayor parte de sus ganancias de la renta de recursos naturales de los cuales se han apropiado bajo condiciones favorables. En las economías emergentes más dinámicas, en cambio, los capitalistas obtienen las suyas de una fuerza de trabajo altamente 
calificada ocupada en la producción industrial de bienes y servicios. En Chile, la mitad de todas las inversiones realizadas en las últimas cuatro décadas se han concentrado en solo dos sectores, minería y generación eléctrica, que en conjunto ocupan aproximadamente el 2\% de la fuerza de trabajo (CENDA, 2011b).

En definitiva, la fuerza de trabajo chilena no forma parte de las prioridades indispensables de los grandes inversionistas, tanto extranjeros como nacionales. Ello explica los elevadísimos niveles de desocupación que han promediado más de un 8\% desde el golpe militar (1973). Sugiere, asimismo, una razón para que el país haya tolerado el continuado desmantelamiento a lo largo de cuatro décadas de su sistema nacional de educación pública, con grave perjuicio de la calificación de la fuerza de trabajo nacional.

En 1981 se implementó un esquema de financiamiento inspirado por Milton Friedman, cuyo objetivo principal es debilitar los establecimientos públicos y subsidiar los privados. Dicho esquema ha sido mantenido hasta hoy en lo esencial, con la complicidad de los tecnócratas y algunos políticos democráticos estrechamente relacionados con los así llamados "sostenedores" educacionales privados. Este concepto bastante poco elegante pretende equiparar de alguna manera a los establecimientos educacionales públicos y privados. Asimismo, iguala entre estos últimos a los que son sin fines de lucro con aquellos que lo persiguen. Seguidamente, el Estado se obliga a tratar a todos los "sostenedores" por igual en todos los aspectos. Olvida de ese modo que es al propietario de los colegios públicos al que abandona a su suerte, al tiempo que estimula generosamente la inversión de propietarios privados en los suyos.

El esquema ha llegado al absurdo de que actualmente el Estado aporta más subsidios educacionales a algunos de estos, especialmente a aquellos que dependen de instituciones religiosas, que los que aporta a sus propios establecimientos (CENDA, 2011c). Ciertamente, no se trata de negar el apoyo público a instituciones educacionales particulares que, como las mencionadas, no tienen fines de lucro. El problema de la política actual no es que subsidie establecimientos privados; su distorsión radica más bien en haber desmantelado el sistema público, cuyo engrandecimiento debería ser su objetivo principal. Peor aún, esto ha sido deliberado: se 
argumenta que colegios y universidades públicas gratuitas y de buena calidad constituyen una "competencia desleal" para la industria de educación privada. Es desleal puesto que una competencia que se base en la gratuidad y calidad ya no hará rentable y sostenible el negocio privado. El fomento de esta última ha sido el verdadero norte durante las últimas décadas, y sigue siéndolo. Es por esta razón, precisamente, que el tema del lucro está en el centro del debate de la calidad.

\section{UNA INVERSIÓN SIN RETORNO: EL “CAPITAL HUMANO" Y EL NEGOCIO ASOCIADO}

El concepto central que inspira la política de privatización es el de "capital humano". A partir de él se asume que el gasto en educación constituye una inversión privada para los educandos, que genera ganancias y rentabilidad como un negocio cualquiera, justificando de este modo el cobro de matrículas.

Las "ganancias" netas podrían medirse por el incremento en las remuneraciones, debido a la mayor calificación, menos el costo de la capacitación requerida para lograrla, ambas expresadas en valor presente. Sin embargo, cuando uno de nuestros endeudados "capitales humanos" se enfrenta en el mercado con el capital de verdad e intenta venderle su ahora calificada fuerza de trabajo, su mal llamado capital, se encuentra con la dura realidad de que no le ofrecerá por ella ni un peso más de lo que vale.

En otras palabras, el capital le paga lo que requiere en ese momento para vivir junto a su familia en las condiciones que se consideren normales para otros "capitales humanos" como él, en ese país y en ese tiempo. El mercado se encargará de que así sea, por simple oferta y demanda, tal como ocurre en el caso de las materias primas, maquinarias y otras mercancías, que el mismo capital compra concurrentemente para organizar un proceso productivo, comercial o financiero.

Otra cosa bien diferente es el valor agregado que nuestro "capital humano" va a incorporar con el sudor de su frente, junto a sus compañeros trabajadores - ahora el capitalista los denomina "mano de obra" -, a los bienes o servicios producidos en el curso del proceso aquel. Ciertamente, va a ser muy superior al valor de 
su fuerza de trabajo, condición indispensable para que los contraten en primer lugar. En eso consiste precisamente el capital: no es una máquina o un edificio, ni mucho menos la fuerza de trabajo, por muy calificada que sea. Es la relación social que se establece mediante la contratación privada masiva de trabajo asalariado con la finalidad de obtener ganancias.

De este modo, nuestro sufrido "capital humano" descubrirá que su negocio no cumplió con las expectativas iniciales. Si es afortunado, el mayor salario debido a su educación terciaria compensará los costos totales de haberla completado, pero lo probable es que guarden muy poca relación con aquella. Sin embargo, lo que sí verá todos los meses es la cuota del crédito que contrató con el banco para solventar sus estudios. El famoso negocio del "capital humano" no es otra cosa que una forma de financiar parte del sistema educacional mediante una suerte de impuesto adicional a la planilla de remuneraciones de los profesionales, igual que la previsión, la salud y el seguro de desempleo.

Se trata de un método de financiamiento económicamente ineficiente y socialmente injusto. Resulta ineficiente, puesto que equivale a poner un impuesto sobre los salarios de los futuros profesionales, lo cual encarece la mano de obra calificada y disminuye la competitividad de las empresas. Es además injusto, porque recae esencialmente sobre la clase media y sectores populares.

\section{SISTEMA DE FINANCIAMIENTO DE LA EDUCACIÓN SUPERIOR: INEFICIENTE, INJUSTO, INSOSTENIBLE, ESCANDALOSO Y PERVERSO}

Considerando las matrículas, el gasto de los 872.849 alumnos de educación superior promedió $\$ 2,7$ millones por alumno durante el año 2009 (US\$ 5.000 aproximadamente). Los 576.600 estudiantes universitarios representaron un gasto promedio anual de $\$ 3,7$ millones por alumno, cifra que en el caso de los 189.069 que estudian en los Institutos Profesionales (IP) se reduce a $\$ 1,1$ millón y para los 107.180 de los Centro de Formación Técnica (CFT) baja a $\$ 459.000$ anuales por alumno.

Por otra parte, según la Dirección de Presupuestos (DIPRES), el financiamiento público a la educación terciaria alcanzó el 2009 a 407.789 millones de pesos de ese año. Suponiendo que el 80\% de 
dicho financiamiento se concentra en las universidades que componen el Consejo de Rectores, el financiamiento público representaría poco más de un quinto de los ingresos totales de las universidades que lo componen, que en sus balances del 2009 declararon ingresos totales de 1,45 billón de pesos anuales.

El gasto público en educación terciaria registrado por DIPRES representa 467.193 pesos por alumno al año. Como referencia, el gasto público en educación superior alcanzaba en 1973 a casi un millón de pesos de hoy por alumno-año, según cifras de CENDA basadas en una serie compilada por la Universidad Católica (CENDA, 2011d). Es decir, hace cuarenta años un Estado y una economía mucho más pequeños que los actuales invertían el doble por alumno de educación superior.

Si bien las instituciones de educación superior, tanto las del Consejo de Rectores de las Universidades de Chile ${ }^{1}$ (CRUCh) como las privadas, obtienen recursos adicionales de empresas, fundaciones y otras fuentes del sector privado, las matrículas y aranceles de los estudiantes representaron el 2009 la enorme suma de 1,43 billón de pesos, lo que representó un 58\% del costo total. Ello equivale a un impuesto de más de 1,43 billón de pesos anuales, que recae sobre las familias que hoy pueden pagarlos y especialmente sobre los futuros profesionales que hoy contratan créditos.

Lo anterior no considera cargos adicionales a las familias, como las multas, intereses penales y otros ítems cobrados especialmente por algunas universidades privadas. Las pocas que registraron esta información reconocieron ingresos de más de 12 mil millones de pesos por este concepto el año 2009 (CENDA, 2011a).

\section{EL ESCÁNDALO DEL CRÉDITO CON AVAL DEL ESTADO (CAE): "DEUDA SIN DIPLOMA"2}

Los CAE fueron creados en junio de 2005 por la Ley 20.027, que establece, entre otras cosas, que la garantía de dichos créditos se comparte entre el fisco y las instituciones de educación superior

\footnotetext{
1 Estas universidades corresponden a las 25 instituciones llamadas "tradicionales", las cuales incluyen propiedades de carácter estatal, privada y religiosa.

2 "Deuda sin diploma" es parafraseado de un informe del Senado de Estados Unidos llamado The Return of Federal Investment in For-Profit Education: debt without diplom.
} 
en que se matriculan los estudiantes. Estas últimas garantizan un 90\% de los créditos de los alumnos de primer año, un 70\% de los de segundo, un 60\% de los de tercero y así sucesivamente hasta llegar a cero cuando los alumnos egresan. El fisco pone el resto de la garantía, es decir, el 10\% en los alumnos de primer año y el 100\% en el caso de los egresados. Esta situación puede resultar desastrosa para universidades privadas con elevada deserción que matriculen una gran proporción de estudiantes con CAE. Por ejemplo, considerando que las "universidades docentes no selectivas de tamaño mayor"3 han adquirido un pasivo equivalente al 53\% de sus matrículas, no sería de extrañar que hicieran egresar a estos alumnos a como de lugar, para sacarse tal fardo de encima y trasladarlo al Estado. De este modo, el CAE está prohijando "profesores barco", como les dicen en México: siempre llevan a buen puerto.

La mencionada ley establece además condiciones que permitan la devolución de los recursos prestados en concordancia con los ingresos futuros del estudiante, vía mandato especial e irrevocable, facultando la deducción de sus remuneraciones y la retención de la devolución de impuestos a la renta en caso de cuotas impagas, renunciando el estudiante al secreto tributario, según sostiene el Informe de Pasivos Contingentes (DIPRES, 2010). En otras palabras, el CAE embarga a los futuros profesionales el sueldo, las devoluciones de impuestos y hasta la privacidad de sus datos.

Este descuento obligatorio resultará insoportable. Según un estudio que el Ministerio de Educación y la DIPRES encargaron al Banco Mundial (2011), la cuota que deberán pagar los alumnos cuando ya estén trabajando equivaldría, en promedio, al 15\% de sus ingresos. Además, el informe señala que ciertos profesionales podrían tener más problemas para estar al día con el crédito: los veterinarios, agrónomos, sicólogos, arquitectos, periodistas y profesores. Los primeros son los que podrían pagar una mayor cuota: como máximo, el 31\% de su sueldo, considerando el nivel de salarios al segundo año después de egresados y un crédito a veinte años plazo. El resto pagaría el 20\% de su sueldo como máximo.

3 Tipología construida por el Aequalis, Foro de Educación Superior (TORRES; ZENTENO, 2011). 
Otras profesiones, como enfermería y algunas técnicas, destinarían el $10 \%$ de su sueldo en promedio. En otras palabras, el pago del CAE representará un gigantesco impuesto a las remuneraciones. Sus "beneficiarios" de hoy tendrán un descuento obligatorio de un 7\% para salud, de un 13\% para las AFP, de alrededor de un 10\% por impuesto a la renta y entre un 10 y un 31\% para pagar el CAE.

Así, también, surge la preocupación de todos aquellos estudiantes que contrataron el crédito y que, posteriormente, debido a numerosas causas, tuvieron que abandonar la carrera seleccionada. Esta misma inquietud es la que también ha emergido en las políticas de educación superior en los Estados Unidos. En efecto, ¿cuál es, en este sentido, el resultado de esta dramática ecuación? Como el mismo título del documento del Senado de este país lo señaló, el corolario de esta situación no es sino una "deuda sin diploma". El detalle, como lo constata el informe, es que son precisamente las instituciones de educación superior privadas y con fines de lucro las que ofrecen este resultado final (US SENATE, 2010).

El monto promedio de los créditos contratados el 2010 fue de 1,46 millón de pesos por alumno. En base a ese promedio, el endeudamiento total de un alumno que cursa una carrera de cinco años será de 7,3 millones de pesos y más de 10 millones si estudia siete años en una carrera de costo promedio. Esta última cifra sube considerablemente y puede duplicarse fácilmente en el caso de alumnos de carreras largas y caras, como medicina, por ejemplo.

Las universidades concentran un 57 por ciento de los "beneficiarios" de CAE y dos tercios del monto otorgado, correspondiendo el resto a los institutos profesionales (IP) y centros de formación técnica (IP). Es decir, poco menos de la mitad de los CAE los han contratado estudiantes de carreras técnicas, que tienen menos de un $30 \%$ de la matrícula total. De este modo, mientras en las universidades acreditadas hay poco menos de un cuarto de alumnos con CAE, esta proporción sube a más de $40 \%$ en los IP y CFT.

Algo parecido se aprecia en las universidades del CRUCh, donde los estudiantes con CAE son menos del 10\%, cifra que se reduce a $8 \%$ en las universidades estatales. En cambio, el $42 \%$ de los estudiantes de universidades privadas acreditadas tiene CAE, cifra que sube a $53 \%$ en las "universidades docentes no selectivas de 
tamaño mayor", que están al fondo de la tabla de calidad. Es decir, quiénes más se están endeudando con el CAE son los estudiantes de familias de menores ingresos, que estudian carreras técnicas y en universidades privadas de menor calidad.

Los grandes beneficiados con el CAE resultan ser, en definitiva, los bancos. En efecto, cobran tasas de $6 \%{ }^{4}$ por créditos avalados doblemente por el Estado y las instituciones de educación superior, y cuyos deudores están obligados a pagar mediante descuentos por planilla y a través de sus devoluciones de impuestos. Dichas tasas resultan más del doble de las que el Banco Central les cobra a los bancos. Sin embargo, lo que adquiere caracteres de escándalo es que, adicionalmente a todo lo anterior, el fisco les recompra a los bancos de inmediato la mitad de la cartera CAE.

Por otra parte, el año 2010, los bancos otorgaron CAE a los estudiantes por un total de 300.011 millones de pesos (DIPRES, 2010). Sin embargo, el fisco les recompró inmediatamente 132.480 millones de pesos. En otras palabras, casi la mitad de los CAE otorgados ese año correspondieron a platas frescas aportadas por el fisco. En el total de CAE otorgados desde 2006 al 2010 se verifica una proporción parecida, puesto que el fisco ha recomprado 250.100 millones de pesos de una cartera total de 658.423 millones de pesos.

Sin embargo, el fisco recompra la cartera a los bancos con un enorme sobreprecio. El 2010, por ejemplo, pagó un recargo de 49.372 millones de pesos, que representaron un 37,3\% de recargo sobre el valor de la cartera recomprada. Entre 2006 y 2010, el fisco ha pagado a los bancos un recargo de 95.338 millones de pesos, que equivale a un recargo de un $38,1 \%$ por encima del valor de la cartera recomprada.

4 Cabe señalar que a partir de un Decreto de Ley se disminuirá la tasa de interés a un $2 \%$, con el objetivo de igualar las condiciones al crédito que tienen los estudiantes de las universidades del CRUCh. Esta rebaja, sin embargo, consigna la transferencia de mayores recursos estatales al sistema financiero. Es decir, no se rebaja la tasa de acuerdo a una nueva administración, en este caso de orden estatal, sino que simplemente se ejecuta un aumento de los fondos que van destinados a los bancos. Esto supone dos cosas: en primer lugar, se traslada el tema del lucro desde las instituciones de educación superior al sistema financiero, y en segundo lugar, implícitamente se reconoce que los aranceles de la educación superior son impagables. 
De este modo, el fisco ha venido recomprando anualmente alrededor de la mitad de los CAE otorgados por la banca, con un recargo de 38\%, lo que para el 2010 sumó 181.833 millones de pesos, es decir, un 44\% del gasto público total en educación superior, que DIPRES estimó para el 2009 en 407.789 millones de pesos. De ese total, como se ha mencionado, un 38\% corresponde a recargos cobrados por los bancos.

El escándalo del Crédito con Aval del Estado dio un nuevo giro con la publicación parcial de los resultados de la licitación 2012. Al calor de las manifestaciones sociales, el costo para el fisco disminuyó, de manera que resulta del todo incongruente con los pagos efectuados durante los años anteriores: el recargo por la cartera CAE recomprada por el fisco a la banca se habría reducido a la sexta parte.

Los resultados de la licitación de 2012 estarían demostrando de este modo que durante los años anteriores el fisco pagó en exceso el equivalente a más de cinco sextos del recargo sobre la cartera recomprada. Entre 2006 y 2010 ello suma un pago excesivo de más de 80.000 millones de pesos.

Este escandaloso mecanismo proporciona al mismo tiempo una propuesta que puede resultar interesante: puesto que el Estado ha financiado ya más de la mitad de los CAE, puede proceder a condonar de inmediato esa parte de la deuda, con lo cual la situación de los actuales "beneficiarios" se aliviaría significativamente. Ello no representaría desembolso fiscal alguno, puesto que este ya se hizo. Naturalmente, esta condonación debería beneficiar a todos los "beneficiarios" del CAE y en mayor proporción a los de menores ingresos. Al mismo tiempo, se debe poner término inmediato a este mecanismo ineficiente, injusto, insostenible y perverso.

\section{SUSTENTO DEL TRABAJO INTELECTUAL}

En el caso de la educación superior hay que considerar un aspecto adicional, que resulta de importancia crucial. Las universidades son mucho más que fábricas de profesionales. Son las instituciones que en la sociedad moderna sostienen a la capa de personas que cualquier sociedad civilizada destina al trabajo intelectual, científico, cultural y artístico. Evidentemente, el pretender 
que los alumnos financien este aspecto del quehacer universitario representa un absurdo. En el caso de Chile, al desmantelar a las universidades públicas, se ha dañado severamente esta institucionalidad, que resulta vital para la economía y la sociedad.

Los académicos e investigadores requieren contratos estables y condiciones de trabajo adecuadas. En el caso de Chile, en cambio, la mayor parte de ellos, incluso en las universidades del Estado, trabajan en el mejor de los casos "a contrata", es decir, con contratos que expiran y deben ser renovados cada año. La mayoría no cuenta ni siquiera con eso, sino que caen en la categoría de "profesores taxis", que deben completar una remuneración sustantivamente baja con diversos contratos precarios en distintos establecimientos, corriendo de uno a otro al finalizar cada clase.

Por estos motivos, financiar la educación principalmente mediante el cobro de matrículas ha sido desechado por todos los países del mundo menos uno: Chile. En la OCDE en su conjunto, por ejemplo, más del 90\% de los alumnos, profesores, académicos e investigadores pertenecen a establecimientos públicos, financiados por el Estado en una proporción similar. Chile es el único país del mundo donde las familias deben aportar la mitad del financiamiento educacional total y cinco sextos de la educación terciaria en general y prácticamente el 100\% en la educación superior técnica.

Una universidad por excelencia combina de modo equilibrado las funciones de docencia, investigación y extensión. Solo cinco de las sesenta así llamadas "universidades" chilenas cumplen con este requisito elemental. Un trabajo de Aequalis, Foro de Educación Superior (2011a) las clasifica como "universidades de investigación". Incluye otras seis en la categoría de "universidades con investigación selectiva", y seis adicionales en la categoría "universidades esencialmente docentes con investigación selectiva".

Las cinco primeras son, en orden de importancia, las universidades de Chile, Católica de Santiago, de Concepción, de Santiago y Austral. Dos son estatales y tres particulares. Las seis que les siguen incluyen otras tres estatales y tres particulares. Todas ellas, al igual que las cinco anteriores, pertenecen al Consejo de Rectores de Universidades Chilenas. Solo en la tercera categoría, "universidades esencialmente docentes con investigación selectiva", logran 
entrar raspando cuatro universidades privadas. Las cuarenta y tres instituciones restantes, que también se rotulan como "universidades", sencillamente no realizan investigación ni extensión significativa. Todas las demás privadas caen en estas categorías, junto a algunas sedes estatales regionales.

La enorme brecha entre unas y otras se puede apreciar en diversos indicadores. De partida, las publicaciones científicas se concentran de manera abrumadora en las cinco primeras y las restantes en las dos categorías que les siguen. Las cuarenta y tres "universidades" de docencia simplemente no tienen publicaciones en revistas de prestigio internacional. Las primeras atienden a un quinto del alumnado universitario, pero concentran un 39\% de los académicos a jornada completa y un $43 \%$ de los que tienen grado de doctor. Correspondientemente, su presupuesto representa el $41 \%$ de los ingresos de explotación de todas las universidades (CENDA, 2011a).

De esta manera, en relación al promedio de las sesenta "universidades" existentes en el país, estas cinco "universidades de investigación" invierten el doble de recursos, académicos a jornada completa y con grado de doctor o doctorados, por alumno. Si se las compara con las dos categorías más bajas del estudio del Foro Aequalis, que concentran un $28 \%$ del alumnado, estas brechas aumentan a cuatro, más de cinco y hasta casi siete veces, respectivamente. Incluso si se las compara con las doce universidades que les siguen, clasificadas en la categoría de "universidades con investigación selectiva", las cinco "universidades de investigación" prácticamente las duplican en presupuesto, académicos a jornada completa y académicos con doctorado, por cada estudiante.

El que casi todas las que se dicen universidades estén acreditadas como tales quiere decir bien poco en este aspecto. El único requisito verdaderamente importante para obtener la acreditación consiste en demostrar que son un buen negocio. Por ejemplo, no se les exige que tengan publicaciones científicas, académicos a jornada completa o con posgrados, entre muchos otros requisitos elementales. De hecho hay once "universidades", todas acreditadas, que informan tener menos de un académico a jornada completa por cada mil alumnos. 
Según el mismo estudio del Foro Aequalis antes citado, la matrícula de las "universidades de investigación" ha aumentado en un 13\% entre 2005 y 2010, mientras que en el mismo período las "universidades esencialmente docentes con investigación selectiva" lo ha hecho en un $51 \%$ y las "docentes no selectivas de tamaño mayor", que se encuentran al fondo de la escala de calidad, han crecido un $81 \%$.

La razón es bien simple: se hace descansar el grueso del financiamiento en los pagos de los alumnos, que malamente alcanzan para financiar la función de docencia, aun a costa de representar una carga insostenible, además de ineficiente e injusta sobre ellos y sus familias. De este modo, desde el punto de vista de mejorar el sistema universitario, el mecanismo de financiamiento basado en los aranceles resulta además perverso.

En las universidades del CRUCh, al que pertenecen casi todas las que realizan investigación y extensión, además de docencia de relativa buena calidad, los aportes de las familias alcanzan a 2,2 millones de pesos por alumno al año, en promedio. Ello no alcanza a cubrir ni la mitad de sus ingresos de explotación (su presupuesto), que ascienden a 4,6 millones de pesos por alumno al año, en promedio. Los estudiantes de universidades privadas, en cambio, que concentran a todas las que hacen solo docencia, aportan en promedio 2,7 millones de pesos por año, lo que alcanza para cubrir en buena forma todo el presupuesto de las mismas, que suma la misma cantidad por alumno.

La crisis del sistema universitario superior recae, por tanto, por igual en los alumnos, académicos y administrativos de las universidades estatales y particulares, en las del CRUCh y las privadas. Sin embargo, la solución es sencilla, como se ha mencionado. Como recomienda la OCDE (2009), hay que aumentar significativamente el presupuesto público, que hoy cubre menos de un 15\% del total según esta fuente. Del 0,4\% del PIB que representa en la actualidad, hay que elevarlo en pocos años al 2\% del PIB que representaba cuarenta años atrás. El incremento hay que destinarlo prioritariamente a consolidar, fortalecer y ampliar las cinco mejores universidades públicas, que evidentemente son las que mejor pueden responder a este desafío. 
Al mismo tiempo, hay que estimular a todas las demás para que se eleven a este nivel. El problema es que el sistema actual de financiamiento promueve exactamente lo contrario: empuja hacia abajo a las pocas universidades que realizan investigación y extensión, estimulando a que todas se conviertan en simples "universidades de docencia". Para que la nivelación se haga hacia arriba es necesario, como propone la OCDE, dirigir la mayor parte de los recursos a fortalecer las instituciones mismas, de modo que puedan ofrecer condiciones estables y adecuadas de trabajo a sus académicos y funcionarios. Muy especialmente, se debe dar un financiamiento basal adecuado a las universidades estatales. Parece una tarea ardua. Sin embargo, es precisamente lo que el país logró realizar durante la Reforma Universitaria: entre 1967 y 1973 se duplicó el sistema universitario, transformando universidades que no merecían el nombre de tales en establecimientos nacionales modernos, comprometidos con el desarrollo del país y el destino de su pueblo y, además, gratuitos. Ello se logró incrementando los aportes estatales a todas las universidades existentes, exigiendo a cambio que realizaran docencia, investigación y extensión; que contrataran académicos a jornada completa con buenas condiciones de salario y trabajo, lo mismo que sus funcionarios; que respetaran la libertad de cátedra y que no discriminaran en el acceso, promoviendo el de los obreros y sectores populares. A todos se les exigió garantizar lo anterior mediante gobiernos internos democráticos, con participación de todos los miembros de la comunidad universitaria, a la cual se respetó su autonomía en estas condiciones. No parece mala idea intentarlo de nuevo, asumiendo y transformando a la vez, desde luego, el actual contexto.

\section{RECONSTRUIR EL SISTEMA PÚBLICO GRATUITO DE EDUCACIÓN TERCIARIA TÉCNICA}

Corea tiene una cobertura de educación superior que alcanza al 95\% (CINDA, 2007). Chile, por su parte, tiene poco más de un 40\% (TORRES; ZENTENO, 2011). Para duplicarla a un $80 \%$ al Estado le basta con gastar apenas un 7,3\% más en educación al año, aparte de invertir en equipamiento 4.400 millones de dólares, cifra que representa apenas un 18\% de 
los Fondos Soberanos acumulados a marzo de $2011 .{ }^{5}$ ¿Cómo se puede lograr esta maravilla? Haciendo extensivo a todo el país el ejemplo del Centro de Formación Técnica de Lota-Arauco, el único del país que es público y gratuito para sus alumnos.

Las cifras anteriores provienen de un cálculo muy sencillo, basado en la información entregada por el Rector del CFT de LotaArauco. Él explica que el CFT funciona en base a un subsidio estatal de 90 UF por alumno, que financia dos años de estudio. Es decir, el subsidio anual por alumno es de 45 UF, lo que equivale a poco menos de un millón de pesos por alumno. Considerando que los matriculados en todo el sistema de educación superior fueron 285.849 alumnos, según el Sistema de Información de Educación Superior (SIES), duplicar esa cantidad cuesta exactamente esa misma cifra, pero expresada en millones de pesos.

Es el único lugar del país donde funciona el modelo de educación pública gratuita en el nivel terciario. Parece una buena idea replicarlo a todo el país. Es precisamente el sueño del Rector del CFT de Lota-Arauco: extender la enseñanza obligatoria de 12 a 14 años, generalizando su experiencia a todo Chile. Explica que ello tendría un impacto notable para reducir la cesantía, que se concentra precisamente en ese segmento de edad.

\section{RECONSTRUIR EL SISTEMA NACIONAL DE EDUCACIÓN PÚBLICA BÁSICA Y MEDIA}

El continuado desmantelamiento del sistema nacional de educación pública construido a lo largo de medio siglo ha procedido en las últimas cuatro décadas, primero mediante su brutal intervención militar, reducción del gasto público a la mitad y de los sueldos docentes a la tercera parte. Seguidamente, se traspasó la mitad del menguado financiamiento a colegios particulares subvencionados mediante el esquema de vouchers y se desperdigaron los públicos por los municipios.

Según los "economistas de la educación", ello debería haber generado un sistema moderno, de buena calidad y costo reducido,

5 Chile tiene actualmente dos fondos: el Fondo de Estabilidad Económica y Social (FEES) y el Fondo de Reserva de Pensiones (FRP). 
impulsado por una vibrante industria de educación privada. Por el contrario, ha resultado en un sistema malo, caro y segregado, que se debate en su crisis terminal. Ciegos y sordos a esta realidad, sus paladines insisten en su esquema fracasado.

El esquema municipalizado evidentemente no da para más. Hasta los propios alcaldes quieren ponerle término. Sin embargo, en lugar de avanzar en la reconstrucción de un servicio nacional, moderno y eficiente, centralizado y descentralizado al mismo tiempo, como cualquier organización racionalmente concebida, los arquitectos y administradores del sistema proponen un paso más en la privatización de los colegios municipales.

Estos insisten en eludir la solución más evidente, conocida y preferida por la abrumadora mayoría de la comunidad escolar y la opinión pública: reconstruir el sistema nacional de educación pública y en breve tiempo dotar a cada barrio de cada ciudad y pueblo de Chile de un buen colegio gratuito, donde todas las familias puedan mandar a sus hijos en la seguridad que van a recibir una educación de excelencia.

La solución de la crisis educacional no vendrá de la mano de los mismos sectores que diseñaron e implementaron el sistema. Como siempre ocurre, los grandes cambios no son impulsados por "los de arriba", que generalmente legitiman las cosas como están. Será la comunidad escolar y la ciudadanía en general quienes dirán la última palabra.

El asunto es plausible. Si hay un colegio público de excelencia y gratuito en cada barrio, instalar un colegio privado simplemente no resulta buen negocio, por mucho subsidio que se ofrezca a la demanda. Eso lo sabe todo el mundo y especialmente los empresarios privados de educación. Distinto es el caso de colegios particulares con una orientación determinada, por ejemplo, religiosa, filosófica, cultural, de colonia, social, etc. Ese tipo de establecimiento siempre ha existido y seguirá existiendo, con o sin subsidio; nadie se opone a que los reciban, si son buenos.

El problema de la educación, por lo tanto, nunca ha sido el de la libertad de enseñanza o el del apoyo público a proyectos de educación particulares. En ese punto todos coinciden. El problema ha sido más bien un esquema que ha pretendido reemplazar el 
sistema de educación pública por empresas privadas con fines de lucro, lo cual evidentemente solo es posible en la medida en que se desmantele el primero para abrir espacio al segundo. Esa ha sido precisamente la esencia de la Ley Orgánica Constitucional de Educación (LOCE) y posteriormente de la LGE y todos sus mecanismos relacionados: la municipalización, el financiamiento mediante vouchers iguales, el financiamiento compartido, etc.

Ante el avance arrollador de esta idea sencilla, impulsada por el movimiento estudiantil del 2011, se levantan voces anunciando el fin del mundo si se termina el lucro en educación, que es otra manera de expresar la idea recién expuesta: iQue va a quedar un millón de estudiantes sin colegio! iQue se va a atentar contra miles de pequeños empresarios de la educación, en su mayoría profesores! Siempre los sectores conservadores afirman que el estado de cosas actual no se puede modificar. Por ejemplo, cuando el gobierno popular propuso dar medio litro de leche a todos los niños chilenos, la derecha preguntó si había tantas vacas en Chile. Ahora chillan con una sola voz: ¡No se puede terminar con el lucro en la educación!

Desde otra perspectiva, se puede reconstruir el sistema nacional de educación pública gratuito en breve tiempo sin un aumento significativo del gasto público, sin que quede un solo niño sin colegio y respetando escrupulosamente los derechos de los empresarios que creyeron en el esquema anterior e invirtieron en educación; incluso, se les pueden abrir mejores oportunidades de negocios. Adicionalmente, desde luego, con un enorme avance en las condiciones de trabajo del gremio más vilipendiado de Chile, al cual se ha pretendido cargar con todos los problemas de un esquema privatizador fracasado: el noble y sacrificado profesorado chileno, constituido en más de dos terceras partes por mujeres.

Una forma sencilla en que se puede realizar la transición consiste en que el Estado asuma directamente la gestión de todos los profesores que ya paga, tanto en el sector municipal como en el particular subvencionado. Como se sabe, la subvención a estos últimos supone que se paga a los profesores un salario igual al de los municipales, lo cual ciertamente no ocurre. En otras palabras, pasar todos los profesores de los colegios municipales y particulares 
subvencionados a ser funcionarios del nuevo servicio nacional de educación pública representa para los últimos un beneficio extraordinario. Y para el Estado no representa costo adicional puesto que ya está haciendo este desembolso.

De este modo quedará constituido en lo fundamental el nuevo servicio de educación pública, es decir, con todo su personal docente ya distribuido en el territorio, incluso con su alumnado respectivo, que es lo esencial. Desde el punto de vista de estos últimos no hay cambios, puesto que siguen con sus mismos profesores, solo que estos dependen ahora del nuevo servicio de educación pública.

Adicionalmente, hay que proceder a establecer las estructuras de supervisión y dirección del nuevo servicio docente a todo nivel, asegurando la debida participación de los poderes locales y las comunidades escolares en su gestión. En dicha estructura tienen cabida por cierto todos los actuales supervisores, directores de colegios, etc., que trabajan en el sector particular subvencionado, los que igualmente son pagados por el Estado y pueden pasar directamente a depender del nuevo servicio. Lo principal en este asunto es que la nueva estructura docente del nuevo servicio sea definida por educadores y no por economistas que de educación no tienen idea y ya han hecho suficiente daño al sector.

Luego hay que resolver el tema de los servicios anexos a la educación, como los edificios, computadoras, aseo, alimentación escolar, bibliotecas, etc. Todo esto se puede resolver con la participación del sector privado. Es la única cosa buena del intento de privatización forzada de los últimos treinta años: se ha desarrollado una industria privada que puede proveer estos servicios.

Empezando por los edificios, que si bien han sido financiados por el Estado mediante generosos subsidios, son hoy de propiedad privada de los llamados "sostenedores", término poco elegante que felizmente quedará solo como un mal recuerdo. Sin embargo, ellos tienen por contrato la obligación de destinar dichos edificios a fines educacionales por un plazo de treinta años. El nuevo servicio puede proceder a arrendar dichos edificios a una tarifa que garantice una rentabilidad razonable a las inversiones propias de su propietario en los mismos, descontado desde luego el subsidio fiscal aportado. Eso dará a los actuales "sostenedores" un ingreso más que interesante, 
por muchos años, y luego quedan como propietarios del terreno y edificio y sin obligaciones.

Adicionalmente, muchos sostenedores son efectivamente profesores, que pueden quedar como directores de colegio u otros cargos en el nuevo servicio, contratados como funcionarios, lo que para muchos puede ser un buen arreglo, especialmente para los pequeños. Adicionalmente, habrá que contratar los demás servicios anexos, algunos de los cuales los pueden proveer quizás los mismos sostenedores. De hecho, este mercado se puede ampliar a los actuales colegios municipales, con lo cual se abre al sector privado un amplio espacio de legítimo lucro en el sistema educacional.

Sin perjuicio de todo lo anterior, el paso de los actuales colegios subvencionados al nuevo sistema público debería ser sobre una base estrictamente voluntaria. En otras palabras, aquellos que deseen continuar operando en las mismas condiciones actuales deberían poder hacerlo. Ciertamente, optarían por esta alternativa los colegios subvencionados sin fines de lucro, como los pertenecientes a iglesias y otros. Posiblemente, algunos colegios subvencionados con fines de lucro - los menos probablemente considerarán que pueden continuar funcionando aun en las nuevas condiciones, en las cuales deberán competir con un colegio público gratuito de excelencia en su mismo barrio. En cualquier caso, parece adecuado promover que en la decisión de seguir o no como colegio particular subvencionado en las nuevas condiciones participe toda la comunidad escolar y no solo el "sostenedor".

De la manera expuesta, se puede garantizar una transición indolora al nuevo sistema de educación pública gratuita, el que se reconstruye sin destruir nada de lo existente, incluido lo que se ha construido en las últimas décadas, sino por el contrario sobre la base de aquello, como debe ser. Ciertamente es solo un camino entre los muchos posibles para lograr este gran objetivo nacional. Seguramente los expertos en la materia pueden sugerir caminos mucho mejores para lograr el mismo fin. Lo importante es precisar que si se quiere, se puede. El país acaba de realizar un cambio mucho mayor: el nuevo sistema de justicia. Lo hizo muy bien, apoyado en un consenso de todos los sectores. Es precisamente lo que hay que hacer con la educación. iEs el momento de hacerlo! 


\section{PALABRAS FINALES}

La educación chilena, en todos sus niveles, necesita imperiosamente de una reforma estructural de los pilares que la sustentan. Las deficiencias y problemas no resueltos, mencionados a lo largo de este artículo, forman parte de la evidencia avasalladora de este cambio posible y necesario.

No se trata simplemente de maquillajes que apunten a resolver las insuficiencias de tipo ético (lucro) o psicológico de los actores que componen este sistema. No se trata de consolidar medidas que funcionan sobre la misma lógica que genera las problemáticas. No se trata de continuar con políticas públicas que privilegian la privatización y el desmantelamiento de la educación pública. No se trata de prolongar las políticas basadas en la caridad (becas). De ese experimento ya hay suficiente argumentos y evidencias que lo invalidan. De lo que se trata, más bien, es de concebir un Sistema Nacional de Educación Pública, sobre el cual descansen conceptos como calidad y equidad. Esto no significa, desde luego, eliminar las instituciones privadas; el objetivo principal es fortalecer y elevar a la categoría de indispensable el contenido de lo público en la educación.

Respecto a la calidad, no se trata meramente de verificar si las instituciones de educación superior cumplen los estándares mínimos que ellas mismas se propusieron de forma autónoma. No se trata, tampoco, de asegurar la calidad a través de mecanismos locales que incentivan la "cultura de la calidad" continúa. El sentido de calidad debiera exigir una mirada sistémica y de largo plazo, donde los proyectos sean coherentes con el conjunto de las IES, y no tan solo con el proyecto educativo particular. La calidad no debiera basarse sobre criterios prestablecidos que se corroboran mediante procesos de acreditación y autoevaluación. La calidad debe asumir la diferenciación institucional y, a partir de allí, orientar las medidas que hagan del sistema de educación algo inteligible y consistente tanto internamente como con su entorno. El contenido de la calidad es más bien global que estrictamente particular.

En cuanto a la equidad, no se trata meramente de declarar que el talento está distribuido de forma homogénea en todos los estratos socioeconómicos. Menos aun de sostener que la combinación 
más eficiente y eficaz para determinar la equidad es su relación con el mérito. El asunto primordial, desde este punto de vista, es la cohesión e integración social en el mundo de la educación; esto es, terminar definitivamente con la segmentación socioeconómica en el sistema de educación, en el cual hay instituciones para sectores con bajos ingresos, otras para ingresos medios y, por último, para ingresos altos. De este modo, y bajo una mirada global, existen instituciones similares que reciben estudiantes similares, los cuales terminan trabajando en puestos de trabajo similares. Esto implica que la pretendida movilidad social, que sostiene el discurso imperante, pierde la sustantividad, desde la mirada sistémica. El contenido de la equidad debe abordar esta problemática, que es quid del asunto, para luego ir resolviendo paulatinamente las otras.

Este camino, como se ha mencionado, es posible y necesario. Posible porque el país está en las condiciones económicas para hacer frente a esta reforma. Necesario porque las desigualdades y brechas permanentes entre las distintas clases sociales ya no son sostenibles en el corto plazo. La educación es la esencia de este cambio en las estructuras sociales.

\section{REFERENCIAS}

\section{BANCO MUNDIAL. Programa Crédito con Aval del Estado} (CAE) de Chile. América Latina y el Caribe. (s.l.): BM, 2011.

CENTRO DE ESTUDOS NACIONALES DE DESARROLLO ALTERNATIVO. Informe financiamiento de la educación superior en Chile: problemas y propuestas. Editor Francisco Durán, colaboradores Pablo Jorquera, Paula Mendonza, Roxana Pey, Manuel Riesco. Santiago, Chile, Ago. 2011a. Disponible en: <http://www.archivochile.com/Chile_actual/01_mse/0/ MSE0_0024.pdf>.

Series CENDA: empleo e remuneraciones: fuerza de trabajo. Santiago, Chile, 201 b. Disponible en: <http://docs. google.com/spreadsheet/ccc?key=0Avg26qqidiXpdDVWQUxPanU 3a09DUEW5R1JfWDdWLWc> 
Series CENDA: Receptores subvenciones escolares.

Santiago, Chile, 2011c. Disponible en: <http://docs.google.com/ spreadsheet/ccc?key=0Avg26qqidiXpdFpJYWw4ZUNtRVJXdG53Ym pPaUkwN3c >.

Series CENDA: Chile 1810. Educación. Santiago, Chile, 2011 b. Disponible em: <http://docs.google.com/open?id=0A vg26qqidiXpdHh4bmtLeldJbmhhT0N3QzhnN1JndIE >.

CENTRO INTERUNIVERSITARIO DE DESARROLLO. Informe iberoamericano de educación superior 2011 . Editor e coordinador José Joaquin Brunner, Editora adjunta Rocío Ferrada Hurtado. Santiago, Chile, 2011. Disponible en: <http://www. universia.net/nosotros/files/Educacio_Superior.pdf>.

Informe iberoamericano de educación

superior 2007. Santiago, Chile, 2007. Disponible en: <http:// www.cinda.cl/download/informe_educacion_superior_ iberoamericana_2007.pdf>.

CHILE. Ministerio de Hacienda. Dirección de Presupuestos. Informe de pasivos contigentes 2010. Santiago. Chile, Dic. 2010. Disponible en: http://www.dipres.gob.cl/572/ articles-70660_doc_pdf.pdf>.

ORELLANA, V. Caracterización social de los estudiantes de educación superior en Chile, en nueva geografía de la educación superior y de los estudiantes. Una cartografía del sistema chileno, su actual alumnado y sus principales tendencias. Santiago, Chile: Foro de Educación Superior Aequalis, 2011.

ORGANIZACIÓN PARA LA COOPERACIÓN Y EL DESARROLLO ECONÓMICO. BANCO MUNDIAL. La educación superior en Chile. Paris, 2009. (Revisión de Políticas Nacionales de Educación). Disponible en: <http://www.ubiobio.cl/varios/ loreto/La_educacion_Superior_en_Chile.pdf>.

RIESCO, M. El derrumbe de un mito: Chile reforma sus sistemas privatizados de educación y pensiones. Santiago, Chile: CENDA, 2007. 
TORRES, R.; ZENTENO, M. L. El sistema de educación superior: una mirada desde las instituciones y sus características, en nueva geografía de la educación superior y de los estudiantes. Una cartografía del sistema chileno, su actual alumnado y sus principales tendencias. Santiago, Chile: Foro de Educación Superior Aequalis, 2011.

UNITED STATES SENATE. Health, Education, Labor and Pensions Committee. The Return on the Federal Investment in forprofit education: debt without a diploma. United States, Sept. 2010. Availabre from: <http://hrkin.senate.gov/documents/ pdf/4caf6639e24c3.pdf>. 